\title{
PRODUÇÃO DO ESPAÇO E MOBILIDADE URBANA: NA CONTRAMÃO DA SUSTENTABILIDADE
}

\author{
G.A.Souza ${ }^{1^{*}}$ \\ 1 Universidade Federal do Amazonas - Programa de Pós-Graduação em Geografia \\ *geraldoalves@ufam.edu.br
}

\section{RESUMO}

No presente artigo discute-se o modelo de produção do espaço urbano no Brasil dos últimos cinqüenta anos, notadamente de dispersão da população por amplas manchas urbanas e suas conseqüências sobre as viagens urbanas, tendo Manaus - Amazonas como referência de análise. Conclui que este modelo é responsável por levar a população a percorrer longas distâncias que, em função dos modos prioritários de transporte (ônibus e veículos particulares), tem sido responsável por lançar na atmosfera enorme quantidade de $\mathrm{CO} 2$ e outros gases do efeito estufa.

PALAVRAS-CHAVE: Urbanização, Mobilidade urbana, Sustentabilidade.

\section{SPACE PRODUCTION AND URBAN MOBILITY: THE COUNTER-HAND OF SUSTAINABILITY}

\begin{abstract}
The present article discusses the urban space production model in Brazil in the last fifty years, especially for dispersion of the population in vast urban spots and its consequences on urban travel, and having Manaus Amazonas as an analytical reference.We conclude that
\end{abstract}

this model is responsible for bringing people to travel long distances, and that on the basis of priority modes of transport (buses and private vehicles), has been responsible for launching the atmosphere huge amount of $\mathrm{CO} 2$ and other greenhouse gases.

KEYWORDS: Urbanization, Urban Mobility, Sustainability. 


\section{INTRODUÇÃO}

Por séculos, a área das cidades permaneceu bastante reduzida. O principal fator de contenção da expansão era a limitada capacidade das pessoas em vencer as distâncias, já que a maioria das viagens era realizada a pé. Mas a difusão do automóvel enquanto meio de transporte impôs profundas transformações sobre a produção do espaço urbano no que se refere à distribuição espacial das atividades humanas; ao modo como o espaço de circulação passou a ser utilizado e ao consumo de recursos destinados aos transportes. A facilidade de abertura de novas vias e novas linhas de circulação estimularam a expansão horizontal das cidades, ampliando o tamanho da mancha urbana.

Se antes a mobilidade da população estava fortemente limitada à capacidade de vencer as distâncias a pé, agora, apoiada em modos rodoviários de transporte, esta capacidade foi bastante ampliada. O consequente aumento da extensão das viagens urbanas tornou os modos de transporte motorizado indispensável à população que habita as cidades.

No presente artigo se discute o modelo de produção do espaço urbano no Brasil nos últimos cinquenta anos, e tendo Manaus - Amazonas como referência de análise. Notadamente há dispersão da população por amplas manchas urbanas e consequências sobre as viagens urbanas.

Entende-se, que as desigualdades sociais são evidenciadas de dois modos principais: a) - a distribuição da população sobre o espaço urbano se dá em função do poder aquisitivo, com as classes média e alta ocupando espaços de melhor centralidade e melhor acessibilidade urbana e as camadas mais pobres ocupando áreas periféricas mais distantes onde, via de regra, os valores de terrenos são menores e; b) - As classes de melhor poder aquisitivo passaram a apoiar a sua mobilidade urbana em veículos particulares e os mais pobres utilizam-se do transporte coletivo. O uso destes modos de transporte fez com que as cidades tornassem grandes emissoras de CO2 e outros Gases do Efeito Estufa - GEE e outros problemas ambientais.

\section{REFERÊNCIAS}

\subsection{Espaço urbano e acessibilidade}

Sem pretender fazer uma análise da economia política da cidade ou da urbanização, é necessário destacar alguns aspectos deste ambiente que influenciam na distribuição da população, visto que é esta distribuição que determina (em última análise) a estruturação do transporte de passageiros, principal objeto de estudo do presente trabalho.

Parte-se do princípio de que as cidades não são obras do acaso (GLAESER, 2011). Elas surgiram e se desenvolveram porque representavam (e continuam representando) a maneira mais econômica que o ser humano encontrou para atender as suas demandas. Isto porque alguns serviços, tais como energia elétrica, sistemas de comunicação, transportes, cuidados com a saúde, educação, água tratada, etc. essenciais à boa qualidade de vida, somente se tornaram possíveis de serem oferecidos em situações de grande concentração de demanda. Em outras palavras: a maior densidade demográfica (se comparada à da zona rural) torna as cidades economicamente viáveis e energeticamente eficientes. Mesmo com os avanços tecnológicos que possibilitaram a extensão de alguns destes serviços ao campo, as cidades não perderam sua importância no contexto da economia como um todo e continuam sendo a melhor forma de universalização de bens, serviços e mercados.

O melhor aproveitamento dos recursos ocorre em cidades cujo Central Business District CBD ou Zona Central de Negócios - ZCN - encontra-se no centro da mancha urbana. Isto porque, na maioria das cidades, a área central foi (e continua sendo), o destino e/ou a origem da maior parte 
das viagens urbanas. Logo, se esta área está no centro da mancha urbana as viagens se tornam, em média, mais curtas, economizando recursos e tempo.

Para Silva (1998), a densidade demográfica economicamente ideal de uma cidade é de mais de 100 habitantes por hectare, devendo ficar entre 300 e 600, dependendo da estrutura do sítio urbano. No modo capitalista de produção a organização interna das cidades é fortemente influenciada pelos interesses do capital, sobretudo o imobiliário. É notória esta influência sobre a expansão das cidades brasileiras a partir do desenvolvimento industrial. A mancha urbana da maioria das cidades cresceu proporcionalmente maior que a população, forçando a queda da densidade demográfica. Pode-se dizer que o esforço do poder público neste período limitou-se a adequar a infraestrutura urbana a esta dinâmica. Os efeitos negativos desta expansão parecem ter sido ignorados pelo poder público que nada fez para contê-la.

\subsection{Estrutura interna das cidades e gastos com transportes}

O espaço urbano pode ser dividido em espaço de moradia, de produção e de circulação e, grosso modo, a área central constitui-se no principal pólo gerador de viagens, estabelecidas entre ela e as zonas intermediárias e periféricas, onde se localizam as residências. Ao aumentar o tamanho da mancha urbana, aumenta também o tempo e os gastos com os deslocamentos e os custos destes.

Souza (2001), apoiado em vários autores desenvolveu um modelo que procura representar a variação do valor do solo, da densidade demográfica e dos custos dos transportes no espaço urbano, tomando como referência um sítio de formato radial, com o CDB localizado no centro da mancha urbana. Nele a mancha urbana foi dividida em CBD, Zona Periférica do Centro (ZPC), Periferia 1, 2 e 3 e Zona Rural (ZR). Ele é representado pela figura 1, a seguir.

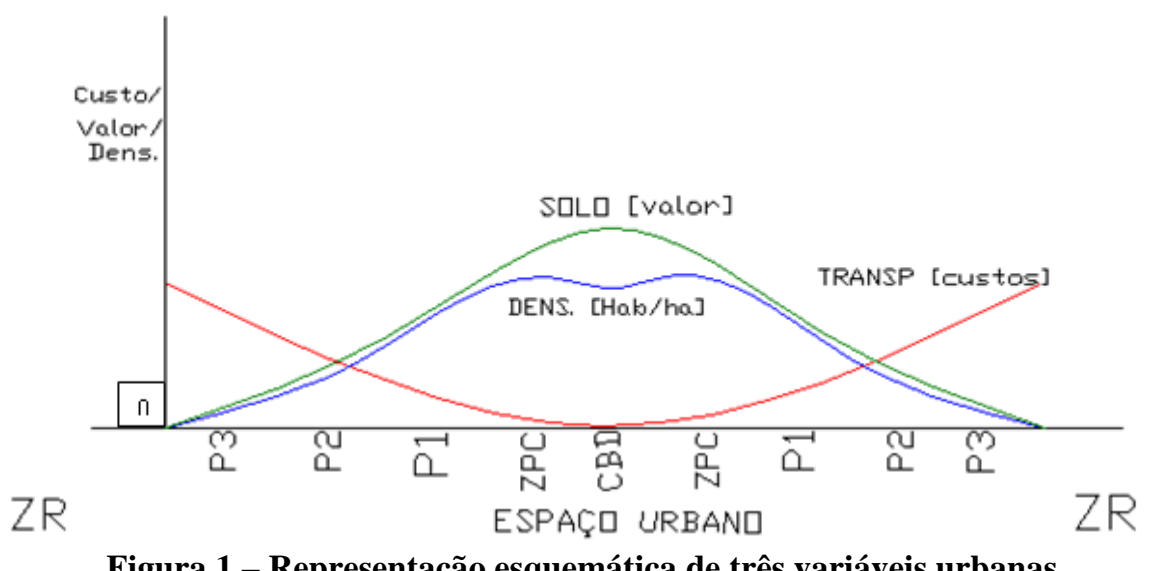

Figura 1 - Representação esquemática de três variáveis urbanas Fonte: Souza, 2001.

Grosso modo, a área central constitui-se no principal pólo gerador de viagens, atraídas das áreas periféricas onde se localizam as residências. Conforme é possível observar na figura acima, o modelo expressa a ideia de que a densidade demográfica e o valor do solo urbano decrescem da área central para as zonas periféricas. A dessimetria entre valor do solo e densidade (na área central) é devido à grande concentração de atividades econômicas, o que limita ou inibe o uso desta para fins de moradia. Na prática, o valor do solo e a densidade demográfica dependem de uma série de fatores, tais como a existência de subcentros, centros de compras, áreas de especulação imobiliária, a infraestrutura viária, os sistemas de transporte, etc.

É fácil concluir que os custos operacionais de uma linha de ônibus mais longa são mais altos que outra de menor extensão: maior quilometragem rodada por mês, maior gasto de 
combustível e maior quantidade de veículos, motoristas e cobradores para manter a frequência adequada. Apesar disso, quase todas as cidades brasileiras adotam um único valor para a tarifa do transporte coletivo. Para os usuários isto significa que os gastos com transporte são os mesmos, independentemente das distâncias percorridas por eles. Das viagens mais curtas, que poderiam custar menos, são retirados valores adicionais que ajudam cobrir os custos das viagens mais longas. Em função deste sistema de tarifação, não faz diferença (do ponto de vista financeiro) residir em bairros mais centrais ou na periferia. Souza (2010) sugere que esta prática força a expansão da mancha urbana, estimulando a população que depende do sistema de transporte coletivo a fixar residência em distantes periferias, dispersando a população. Ferraz et ali (1991) estudou a influência que a densidade demográfica exerce sobre os custos do transporte coletivo de diferentes formas de sítios urbanos. A figura 02 mostra esta variação para cidades de formato circular.

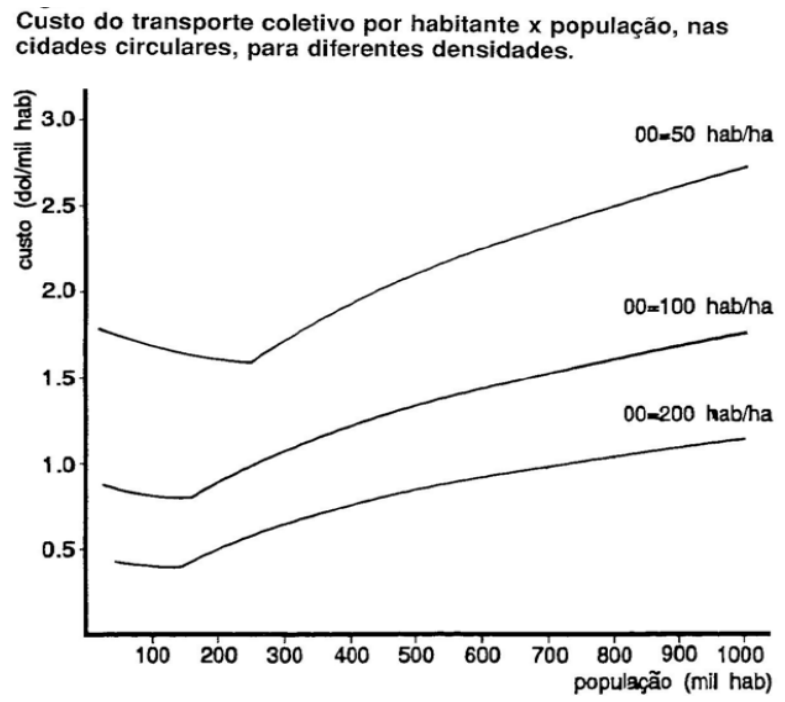

Figura 02 - Custo do transporte coletivo X densidade demográfica.

Fonte: FERRAZ et al., 1991.

Para Vasconcellos (2013), com o aumento da mancha urbana "as viagens tornam-se mais longas, com maior consumo de tempo de deslocamentos e de energia, e maior emissão de poluentes. A produtividade do transporte coletivo cai, aumentando seus custos de operação e consequentemente o valor da tarifa a ser cobrado do usuário".

Considerando que morar tão longe leva a um tempo adicional dedicado às viagens urbanas, o local de moradia impacta negativamente estas famílias, visto que este tempo poderia ser utilizado para qualificação. E, menos qualificados, as oportunidades de acesso ao mercado de trabalho também são menores. A conclusão do autor foi que a tarifa a preço único leva a um círculo vicioso entre condição social e local de moradia: vão para a periferia porque são pobres e porque as oportunidades são menores para quem vive na periferia, são menores as chances de ascensão social.

\subsection{A (In)sustentabilidade da mobilidade urbana}

Segundo Carvalho (2011), ao se deslocar sobre o espaço urbano o passageiro é responsável por emissões de $\mathrm{CO}_{2}$ e outros gases para a atmosfera, cuja quantidade varia de acordo com o modo de transporte utilizado. A variação pode ser ilustrada com dados de $\mathrm{CO}_{2}$, conforme segue: 3,5; 16,0; 71,1 e 126,8 gramas de $\mathrm{CO}_{2}$ por passageiro por quilômetro percorrido se a viagem for realizada por metrô, ônibus, motocicleta ou automóvel, respectivamente. Assim, passageiros que realizam as viagens urbanas utilizando metrô ou ônibus são responsáveis por quantidades bem menores de $\mathrm{CO}_{2}$ que aqueles que viajam em veículos particulares. 
Em função da baixa densidade demográfica (característica da maioria das cidades brasileiras), não resta outra opção ao transporte urbano a não ser por ônibus ou veículos particulares, visto que a dispersão da população inviabiliza a implantação de modos de média e grande capacidade de transporte, tais como o Veículo Leve sobre Trilho - VLT e metrô, modais de transporte público de melhor aceitação pela população e de maior eficiência energética.

\subsection{Expansão horizontal das cidades e transporte urbano}

Analisando o processo de metropolização dos Estados Unidos, Muller (2004), divide-o em quatro períodos: I) Desde o surgimento da cidade até o inicio do transporte ferroviário; II) Um período representado pelo transporte ferroviário intraurbano; III) Outro a partir da introdução dos automóveis e ônibus e, por último, IV) O período a partir do estabelecimento de grandes eixos rodoviários de integração intermunicipal. A figura 2 ilustra este modelo.

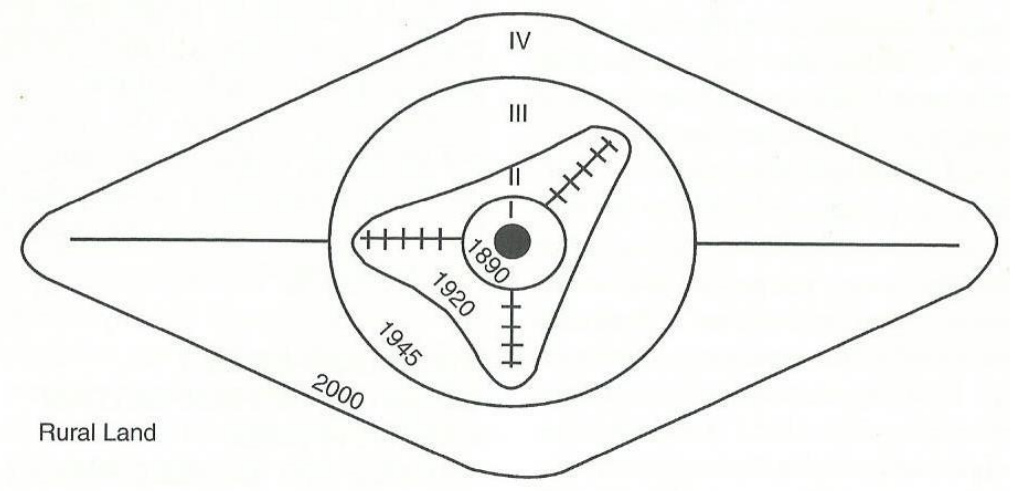

Figura 2 - fases do crescimento metropolitano dos Estados Unidos. Fonte: Muller, 2004.

Até a introdução do transporte ferroviário a extensão do espaço urbano estava limitado à caminhada a pé. A introdução do transporte ferroviário de passageiros permitiu maior expansão urbana, acompanhando os eixos ferroviários. Com a introdução dos automóveis e ônibus as cidades romperam as amarras à expansão horizontal, crescendo em um primeiro momento em torno das áreas centrais e por últimos estimuladas pelos grandes eixos rodoviários de ligação interurbana. Este modelo serve em parte para explicar a realidade brasileira, muito embora aqui a influencia das autoestradas na expansão urbana seja menos pronunciada.

A facilidade para vencer distâncias maiores, seja utilizando o automóvel ou através do transporte coletivo por ônibus (cuja facilidade de implantação de novas linhas e alteração de itinerários é maior que os sistemas sobre trilhos) tornou possível estabelecer unidades urbanas (fábricas, unidades prestadoras de serviços e residências) em locais cada vez mais distantes da área central.

Apoiada na indústria automobilística, a construção de Brasília forçou o estabelecimento de eixos rodoviários de penetração, ligando a nova capital federal às diferentes regiões do país. A opção pelo modal rodoviário fez crescer a indústria automobilística e o processo de urbanização assegurou a disponibilidade de mão de obra urbana e expansão do mercado de consumo de produtos duráveis. A expansão dos meios de transporte possibilitou a penetração da produção dos grandes centros urbanos sobre áreas de economia natural, promovendo fortes transformações sobre o modo de vida da população do interior do país e assegurando a expansão do mercado consumidor dos produtos industrializados, ao mesmo tempo em que acentuava a Divisão Territorial do Trabalho. As 
desigualdades regionais foram se acentuando, com o sudeste se consolidando como região mais dinâmica da economia nacional e as demais regiões desempenhando papel secundário.

Com a geração de empregos e a redução dos custos de produção, o automóvel se converteu em produto de consumo de boa parcela da sociedade. Por outro lado, o automóvel (e o sistema de transporte coletivo, principalmente por ônibus) melhorou as condições de transporte urbano, possibilitando a construção de conjuntos habitacionais afastados da mancha urbana. Para Dyckman (1972), esta ampliação da mancha urbana serviu para justificar o uso do automóvel como meio de transporte e assim assegurar expansão deste mercado.

Considerando as vias como bens públicos destinados à circulação, relações democráticas somente são estabelecidas quando a todos os cidadãos são asseguradas iguais condições de uso destes espaços. Porém, com o advento do automóvel, o acesso e uso destes espaços foi fortemente alterado, com enormes consequências sobre a mobilidade da população. A partir desse momento é possível falar em luta pela apropriação do espaço de circulação.

Pode-se dizer que no Brasil, a mobilidade de parcela da sociedade tem aumentado às custas da redução da mobilidade da grande maioria. Isto porque, não dispondo de meios para assegurar ampla mobilidade à totalidade da população, os governos tem privilegiado a mobilidade daquela parcela da sociedade com maior influência política. Ao restante é oferecido um serviço de baixa qualidade e que consome várias horas semanais nos deslocamentos diários. Em muitos casos, dadas às condições, custos e tempo dedicados às viagens urbanas, muitas pessoas acabam aceitando empregos de menor remuneração, mais próximos às suas residências (Hine, 2009).

Para Vasconcellos (1998), enquanto as famílias de renda mais baixa tem uma mobilidade limitada e consomem menos espaço, as famílias de renda mais alta utilizam transporte mais rápido (o automóvel) para realizar maior número de viagens, consumindo mais espaço. Nas cidades contemporâneas, quanto maior é o sistema viário e mais fácil a compra e a utilização do automóvel, mais eficiente é a reprodução das classes de maior poder aquisitivo. Ao contrário, quanto maior o sistema de transporte público e mais barato, mais eficiente é a reprodução da classe trabalhadora. Assim, políticas públicas que privilegiam a circulação dos automóveis acabam por favorecer as classes de melhor poder aquisitivo (VASCONCELLOS, 1998).

Os congestionamentos, muito comuns em grandes centros urbanos, afetam de modo diferente os donos de automóveis e os usuários do transporte coletivo por ônibus. A retenção impacta de modo bem mais perverso os usuários do transporte coletivo do que os de automóveis sob dois aspectos principais: I) o desconforto enfrentado durante a viagem. O ambiente interno dos dois modais é bastante diferente e confere níveis de conforto, disponibilidade de assento, salubridade, barulho, entre outros, igualmente diferentes etc; II) possibilidade de mudança de itinerário. Este é um aspecto importante visto que, enquanto o usuário do automóvel dispõe da possibilidade de alterar o itinerário, fazer paradas intermediárias ou até mesmo interromper a viagem por algum tempo, o passageiro do transporte coletivo permanece cativo ao itinerário, seja este afetado ou não por congestionamentos de trânsito.

\section{5 - Reestruturação produtiva e transporte urbano}

Uma das principais consequências da reestruturação da economia brasileira iniciada na década de 1990 foi a redução do mercado de trabalho. Muitos postos de trabalho foram fechados e funcionários, com décadas de empresa, dispensados. A retração do mercado de trabalho por um lado e a disponibilidade de capital (resultado de poupança, rescisão contratual e fundo de garantia) por outro, possibilitaram a abertura de empresas de caráter familiar e o setor de transporte foi 
responsável pela absorção de alguns destes novos empreendedores, alojados no que passou a ser denominado como transporte alternativo ou clandestino.

Com a implantação do Plano Real, verificou-se um acentuado crescimento da frota de veículos particulares, em função da facilidade de importação, de financiamento e até mesmo pelo lançamento de modelos acessíveis à classes mais baixas de nossa sociedade. Este fator, aliado ao crescimento do transporte clandestino (além do aumento do desemprego, queda do poder aquisitivo, etc.) fez cair o número de usuários do transporte coletivo oficial e aumentar o uso do transporte individual.

Por estarem sujeitos às mesmas condições de trânsito que os demais veículos, os ônibus não conseguem ser eficientes, manter os horários e o bom desempenho no trânsito. Para disponibilizar ônibus para os usuários em intervalos de tempo aceitáveis, o sistema é forçado a aumentar a quantidade de ônibus por linha, agravando ainda mais as condições do trânsito e elevando os custos. Quando estes custos são repassados para os usuários através das tarifas, o serviço se torna menos competitivo. Em função da baixa qualidade deste serviço, o cidadão proprietário de veículo não utiliza o transporte coletivo e, ao colocar seu veículo na rua, contribui para agravar ainda mais as condições do trânsito.

As políticas adotadas pelo governo federal no início deste século para estimular a indústria automobilística está sendo responsável pelo aumento da frota de veículos em circulação nos grandes centros urbanos, com forte impacto sobre a mobilidade urbana e sobre a qualidade de vida da população. Ao mesmo tempo em que se assiste ao aumento da frota de veículos particulares, nota-se a deterioração da qualidade do transporte público. Parece até uma articulação ardilosa para forçar o aumento das vendas deste setor da economia.

\section{MATERIAIS E MÉTODOS}

Como apresentado acima, o presente trabalho busca analisar o efeito da dispersão da população por amplas manchas urbanas e os aspectos contrários ao desenvolvimento sustentável decorrentes deste modelo, tendo a cidade de Manaus, no Amazonas como objeto de análise e ilustração.

Tomou-se o crescimento da população e da mancha urbana da cidade a partir da implantação da Zona Franca até estimativa da população de 2005 para reconhecer a variação da densidade demográfica da cidade ao longo deste período.

O Plano de Desenvolvimento Local e Integrado - PDLI de Manaus foi publicado em 1975 e esteve em vigor até 2002 quando outro Plano Diretor foi aprovado para a cidade. Algumas vias expressas previstas naquele plano deixaram de ser construídas, com forte impacto sobre a mobilidade urbana da cidade que conta, atualmente com um sistema viário incompatível com o tamanho da mesma - mais de dois milhões de habitantes. Soma-se a isto o fato de glebas de terras terem sido deixadas para traz, tais como a colônia japonesa, reserva do Campus da Universidade Federal do Amazonas, do Centro de Instrução de Guerra na Selva e do aeroporto Eduardo Gomes, o que também influencia na circulação urbana. Utilizou-se uma imagem de satélite para destacar destas unidades na cidade, conforme figura 03. 


\section{RESULTADOS E DISCUSSÃO}

A partir da implantação da Zona Franca em Manaus a cidade passou a apresentar elevados índices de crescimento econômico, demográfico e da mancha urbana. Segundo dados do IBGE, a densidade demográfica de Manaus caiu de 112 habitantes por hectare em 1970 para menos de 40 em 2005, conforme pode ser observado na tabela 1 .

\begin{tabular}{l|r|r|r|r|r|r}
\hline & \multicolumn{1}{|c|}{$\mathbf{1 9 7 0}$} & $\mathbf{1 9 8 0}$ & \multicolumn{1}{c|}{$\mathbf{1 9 9 1}$} & $\mathbf{1 9 9 6}$ & \multicolumn{1}{c|}{$\mathbf{2 0 0 0}$} & \multicolumn{1}{c}{$\mathbf{2 0 0 5}$} \\
\hline População & 283.685 & 611.763 & 1.006 .585 & 1.138 .178 & 1.397 .768 & 1.644 .690 \\
\hline Área [ha] & 2.532 & 11.545 & 30.000 & $37.737,52$ & $37.737,52$ & $44.130,42$ \\
\hline Densidade hab/ha & 112 & 53 & 33,5 & 30,2 & 37,01 & 37,26 \\
\hline \multicolumn{7}{c}{ Tabela 01 - Manaus: evolução urbana, de 1970 a 2005. } \\
Fonte: Censos demográficos, contagem e estimativa da população.
\end{tabular}

Conforme é possível observar, a expansão horizontal da cidade a partir da implantação da Zona Franca impôs uma acentuada queda na densidade demográfica, estando atualmente bem abaixo nos níveis ideais para o estabelecimento de economias urbanas, conforme apontado por Silva (1998). Como já mencionado, os prejuízos econômicos e ambientais causados por este dispersão são consideráveis.

O uso intenso do automóvel em viagens urbanas tem duas consequências sobre a qualidade de vida e sobre o ambiente urbano: I) - intenso uso do sistema viário para um baixo índice de ocupação dos veículos. Esta ineficiência, além de comprometer o desempenho do transporte público por ônibus, gera congestionamentos de trânsito, imobiliza parte da população que passa a ter dificuldade de atravessar as vias e causa muitos acidentes, principalmente sobre os pedestres (atropelamentos); II) - maior índice de gases poluentes por quilometro percorrido por pessoa.

Dados da divisão modal das viagens urbanas de Manaus mostraram que os automóveis são responsáveis por $12,0 \%$ delas. Motos realizam 2,0\%; o transporte coletivo $56,0 \%$ e a pé são $28,0 \%$ (AMAZONAS, 2011). Se atualmente a densidade demográfica de Manaus fosse da ordem de 200 habitantes por hectare, a mancha urbana seria de um quarto do tamanho atual. Mais adensada, as viagens seriam mais curtas e a participação da caminhada, do uso de bicicletas e do transporte coletivo seria em percentuais mais elevados. A atual dependência de modos rodoviários motorizados de transportes seria menor, o que representaria menor quantidade de GEE liberados para a atmosfera.

\subsection{Viagens urbanas}

Em função da inobservância do PDLI, a formação da maior parte dos bairros ocorridos sob esta lei acabou se dando de forma espontânea, sem o menor planejamento. A cidade chegou ao século vinte e um com um sistema viário incompatível com a sua realidade atual. Os congestionamentos de trânsito, muito comuns nos dias atuais decorrem, em grande parte da escassez de vias arteriais. Há com isto um reduzido número de opções de alternativas, o que concentra o fluxo de veículos, levando aos congestionamentos.

Há em Manaus duas áreas que concentram boa parte das viagens urbanas atraídas e/ou geradas: I) a área central, com predomínio de unidades de comércio e serviços; b) O Pólo Industrial de Manaus - PIM, ou Distrito Industrial, localizado na porção sudeste da mancha urbana. A extensão das viagens urbanas para ligar estas duas áreas aos bairros residenciais é considerável. Além da extensão, o arranjo do sistema viário (fortemente influenciado pela rede de drenagem e por alguns vazios urbanos) dificulta a circulação entre estas áreas e os bairros residenciais. 
$\mathrm{Na}$ figura 3 destacam-se quatro áreas da cidade que desarticulam o sistema viário: uma área a sul do aeroporto Eduardo Gomes, o CIGS, o campus da Universidade Federal do Amazonas UFAM e a colônia japonesa. Esta última começou a ser urbanizada recentemente com a abertura de uma grande avenida e a implantação de condomínios residenciais.

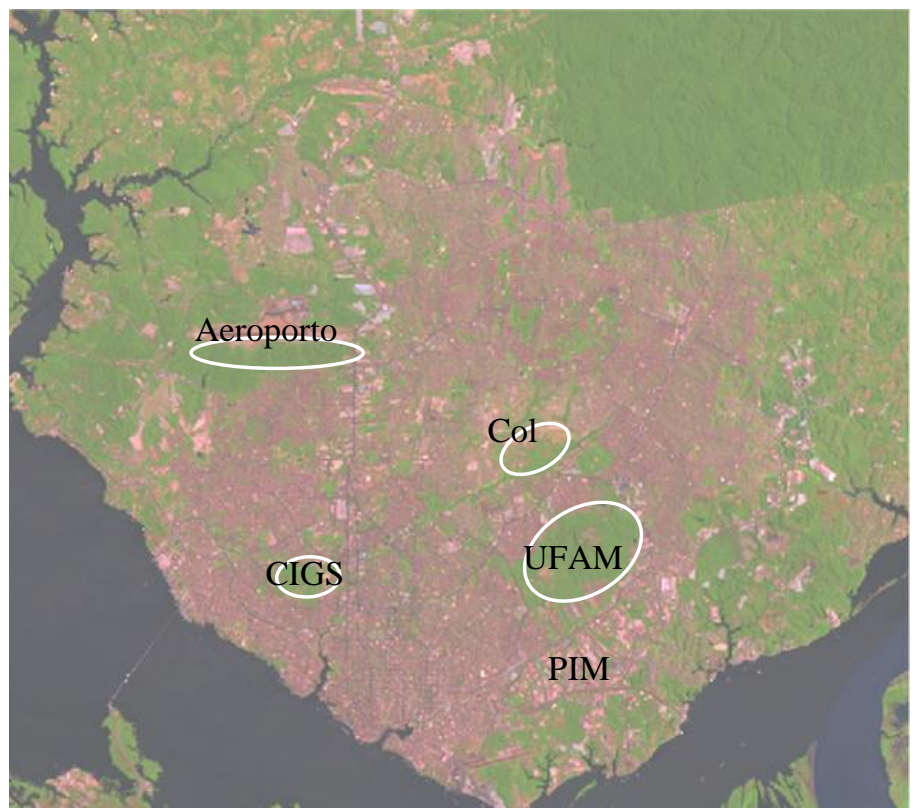

Figura 3- Manaus. Imagem Landsat 5 TM RGB543, de 31 de agosto de 2011. Fonte: INPE

Estas áreas exercem influência sobre o trânsito e mobilidade urbana de Manaus em função do limitado número de vias de conexão entre o sul, onde está localizado o Distrito Industrial e o norte da cidade, notadamente uma área residencial.

\section{CONCLUSÃO}

Ao contrario do que às vezes se pensa, o adensamento não é problema para as cidades. Pelo contrário, ele representa melhor eficiência no uso dos recursos e do tempo das pessoas. Concentrar a população em espaços reduzidos facilita o atendimento de suas demandas.

A expansão das cidades se deu para além da necessidade e atualmente se desperdiçam grandes somas de recursos em infraestrutura urbana, energia, tempo e material para atender as necessidades da população. No Brasil, o acelerado aumento da frota de veículos particulares das últimas décadas tem contribuído para agravar ainda mais as condições de circulação urbana. Os congestionamentos de trânsito (cada vez mais frequentes), além de representar aumento na quantidade de emissões de GEE, impõe considerável perda de tempo nos deslocamentos diários, principalmente dos usuários do sistema de transporte público. As desigualdades sociais e os impactos ambientais caminham na contramão do desenvolvimento sustentável.

A atual dispersão da população de Manaus não pode inviabilizar a implantação de modos de maior capacidade de transporte urbano. Mesmo que a princípio a demanda esteja abaixo do nível ideal, deve-se estimular para que com o passar dos anos se consiga promover a ocupação de espaços vazios intraurbanos e com isto melhorar a eficiência de um sistema de transporte público de grande capacidade. Neste sentido, o ideal é que a cidade pare de expandir a sua mancha urbana e todo o 
crescimento que vier a ocorrer (tanto pelo crescimento vegetativo de sua população quanto pelas imigrações que a cidade continua atraindo), seja abrigado na cidade atual. Isto levará ao aumento da densidade demográfica e com ela, melhor utilização dos recursos e redução dos níveis de emissões per capita de GEE.

\section{REFERENCIAS}

AMAZONAS. Dados da mobilidade urbana de Manaus. Manaus: Secretaria de Estado do Planejamento - SEPLAN, 2011.

CARVALHO, Carlos H. R. Emissões relativas de poluentes do transporte motorizado de passageiros nos grandes centros urbanos. Brasília: IPEA, 2011.

DYCKMAN, J.W. Cidades: a urbanização da humanidade. Rio de Janeiro: Jorge Zahar, 1972.

FERRAZ, A. C. P, SILVA, A. N. R. e FELIX, J. B. Custo do transporte público X tamanho e forma das cidades. Revista dos transportes públicos. ANTP, Ano 13, n. 52, jun 1991.

GLAESER, E. L. Os centros: a maior invenção da humanidade - como as cidades nos tornam mais ricos, inteligentes, saudáveis e felizes. Rio de Janeiro: Campus/Elsevier, 2011.

HINE, J. Transport and social justice. IN: KNOWLES, R; SHAW, J E DOCHERTY, I. Transport Geographies mobilities, flows and spaces. Oxford: Blackwell, 2009.

IBGE - Instituto Brasileiro de Geografia e Estatística. Censos demográficos, contagem e estimativa da população. Diversos anos.

MULLER, P. O. Transportation and urban form - stages in the spatial evolution of th american metropolis. IN: HANSON, S e GIULIANO, G. The Geography of urban transportation. New York: The Guilford Press, 2004.

SILVA, A. N. R. Sistemas de informações geográficas para planejamento de transportes. 1998. Tese (LivreDocência) - Escola de Engenharia, Universidade de São Paulo: São Carlos, 1998.

SOUZA, G. A. Estudo da acessibilidade do transporte coletivo de Manaus utilizando um Sistema de Informação Geográfica. Rio Claro: Unesp, 2001. (dissertação de Mestrado)

Transporte público a preço único: reforçando as desigualdades sociais. In: $4^{\circ}$ Congresso Luso-brasileiro para o planejamento urbano, regional, integrada, sustentável. Anais... Faro, Portugal, 2010.

VASCONCELLOS, E. A. Transporte, espaço e equidade - análises das políticas públicas. São Paulo: NetPress, 1998.

Políticas de transporte no Brasil: a construção da mobilidade excludente. Barueri: Manole, 2013. 